\title{
Un proyecto de nuevo gobierno para las provincias occidentales del Pacífico novohispano
}

\author{
MARÍa ÁNGELEs GÁlvez RuIZ \\ Departamento de Historia Moderna y de América \\ Universidad de Granada \\ magalvez@ugr.es
}

\begin{abstract}
Resumen
Un proyecto hacia la mitad del siglo XVIII de poner bajo un solo gobierno a las provincias occidentales novohispanas del Pacífico, responde a la necesidad de establecer un mayor control a lo largo de sus costas, expuestas a un comercio de contrabando o ilícito que afectaba a un extenso territorio con gran variedad de rutas y mercados regionales, ubicados en su mayoría en los límites jurisdiccionales de la audiencia de Nueva Galicia. Los informes de autoridades portuarias como el castellano de Acapulco, o dictámenes como el emitido por el fiscal de la audiencia de México ofrecen miradas particulares sobre este proyecto, así como una rica información complementaria de los litorales noroccidentales. Aunque la presencia de barcos extranjeros en las costas neogallegas y la rivalidad imperial explican en parte el surgimiento de tales proyectos, otros intereses regionales y objetivos políticos y económicos de mayor alcance pueden explicar el fracaso de la propuesta.
\end{abstract}

Palabras clave: Nueva Galicia; Audiencia de Guadalajara; costas y puertos noroccidentales; Pacífico; defensa del litoral.

\section{A New Government Project for the Western Provinces of the Novohispanic Pacific}

\begin{abstract}
A mid-18th century project to bring the Western provinces of the Novo-Hispanic Pacific under a single government responds to the need to establish greater control over its coasts, exposed to smuggling or illegal trade involving a vast territory with a great variety of routes and regional markets, located mostly within the jurisdictional limits of the audiencia of Nueva Galicia. Reports by port authorities such as the Castilian Report on Acapulco, or verdicts such as the one issued by the prosecutor of the audiencia of Mexico offer particular views on this project as well as rich additional information on the northwestern coasts. Although the presence of foreign vessels on the coasts of Nueva Galicia and imperial rivalry partly explain the emergence of these projects, other regional interests and political and economic objectives of greater scope may account for the failure of the proposal.
\end{abstract}

Key words: Nueva Galicia; Audiencia of Guadalajara; northwestern coasts and ports; Pacific; coastal defense.

Fecha de recepción: Fecha de aceptación: 


\title{
Un proyecto de nuevo gobierno para las provincias occidentales del Pacífico novohispano
}

\author{
María Ángeles Gálvez Ruiz
}

\section{INTRODUCCIÓN}

$\mathrm{E}$ 1 presente trabajo sobre las provincias occidentales de México cuyas costas se encuentran bañadas por la Mar del Sur está basado en un expediente del año 1752 en el que se estudiaba la posibilidad de establecer un nuevo gobierno en las provincias de Motines y Colima, y otras pertenecientes a Nueva Galicia que formaban parte del arco geográfico de las costas noroccidentales del Pacífico. ${ }^{1}$ Los objetivos propuestos son, en primer lugar, determinar las causas que llevaron a determinar tal propuesta a mediados de la centuria ilustrada así como las razones de su fracaso; y en segundo término, realizar un acercamiento a la realidad de aquellas regiones costeras, valorando la importancia y funcionalidad de sus encla-

${ }^{1}$ Testimonio de los autos fechos en virtud de Real Cédula sobre si será conveniente que se pongan las Jurisdicciones de Motines, Colima, Sayula, Zapotlán, Autlán, Amula y Exsatlán, vajo un solo Gobernador, a cuio cuidado se pueda poner, como el que está a la vista el que dé las Providencias más promptas para impedir el comercio de los olandeses, y otros estrangeros. Superior Gobierno, año de 1752. México 1.349. Archivo General de Indias (AGI), Sevilla. Tuvimos noticias del documento por la transcripción y el estudio preliminar que Serrera (1979, pp. 169-170) hizo de la descripción del distrito de Colima del año 1752. ves portuarios, fondeaderos y otros surgideros en las rutas del Pacífico. El estudio propuesto nos ha permitido calibrar la importancia que llegaron a adquirir aquellas provincias occidentales y sus litorales hacia mediados del siglo XVIII.

Buena parte de las costas occidentales novohispanas fueron objeto de atención dos siglos antes al abrirse la ruta que uniría las Filipinas con Nueva España, convirtiéndose entonces las de Jalisco en el testigo del paso del galeón de Manila en el virreinato, pues una vez avistado el cabo de San Lucas, el galeón atravesaba el Mar de Cortés hasta alcanzar las costas jaliscienses rumbo a Acapulco (Bernabeu, 1992, p. 69). ${ }^{2}$ Una larga travesía llena de esperanzas, descubrimientos y también muchas penalidades donde aquellas costas eran abrigo para superar odiseas y accidentes frecuentes.

La causa que dio origen a la real cédula fechada el 31 de octubre de 1750 fue la alarma que generó el arribo de dos navíos holandeses a aquellas costas en el año 1747, motivo por el que se ordenaba al

${ }^{2}$ Entre los numerosos estudios sobre el Pacífico y la Nueva España destacamos los de Bernabeu (2013); Bonialian (2012); Yuste (2007). Y sobre las costas novohispanas del Pacífico, Pinzón (2011); Olveda (1996); Olveda y Reyes (1994). 
virrey, el conde de Revillagigedo, se elaborara un informe, que después pasaría al dictamen de un fiscal, para que analizara la conveniencia de establecer un nuevo gobierno en las provincias de Motines, Colima, y las novogalaicas de Sayula, Zapotlán, Autlán, Etzatlán, Amula, Purificación, Tepic, Acaponeta y Sentispac, tan expuestas a la presencia o al ataque de barcos extranjeros.

Su puede decir que los ánimos estaban singularmente encendidos desde la presencia de los ingleses en las costas novohispanas en el año 1742, y la captura un año después del galeón Nuestra Señora de Covadonga en las cercanías de Filipinas por George Anson.

En cuanto al nuevo gobierno mencionado en la real orden, la principal novedad radicaba en su independencia de las directrices novogalaicas y de su audiencia, poniéndolo bajo supervisión directa de la capital virreinal. Una copia de la real cédula se incluye en el Testimonio de los Autos, ${ }^{3}$ donde el escribano mayor Martínez de Soria daba fe de la real cédula cuyo original era devuelto a la Secretaría de Cámara del virreinato. Las razones expuestas por el Consejo de Indias eran claras y precisas, pues destacaba la necesidad de impedir el comercio de los extranjeros en aquellas costas, así como evitar elevados gastos a la Real Hacienda por la multiplicación de despachos de correos que se daban cuando tenían lugar hechos como estos. También añadía el Consejo dar protección a los naturales ante posibles acciones de saqueo.

Propuestas de este tipo no fueron ni las primeras ni las últimas del siglo XVIII en Nueva España, incluso desde el qui-

\footnotetext{
${ }^{3}$ México. 1.349, fs. 1r-3v. AGI, Sevilla.
}

nientos se planteaba la idea de crear otro reino o virreinato en el norte de México, tanto por la creencia que se tenía de las riquezas existentes en aquellas lejanas tierras como por la necesidad de colonización de un extenso territorio poblado de indios indolentes (Velázquez, 1977, p. 164). También las distancias al centro de México pesaron para que se pensara en proyectos de esta naturaleza. Finalmente el tema concluyó con la creación de la Comandancia General de la Provincias Internas en 1776 como nueva división político-militar en el norte. No obstante, algunos pasos previos se dieron en la primera mitad de siglo afectando a la jurisdicción de la audiencia de Guadalajara en su parte norte. El ámbito de actuación del tribunal era enorme pues desde el siglo XVII abarcaba los reinos de Nueva Galicia y Vizcaya; más tarde ejerció jurisdicción sobre Nuevo México y las Californias, y para el siglo XVIII también tuvo competencias sobre Ávalos, Zapotlán, Amula, Autlán y Etzatlán (Muriá, 1988, pp. 135-137). Los recortes no vinieron hasta 1734 que, segregando la región de Culiacán de Nueva Galicia, se erigió la provincia de San Felipe y Santiago de Sinaloa con un gobernador y capitán general a las órdenes directas del virrey. Para 1750 ocurrió otro tanto al descubrirse las minas de Bolaños con lo cual "se revitalizó el antiguo Gobierno de las Fronteras de San Luis de Colotlán, a efecto de que sus riquezas pasasen directamente a Nueva España” (Muriá, 1994, p. 58).

A mediados de la centuria ilustrada, con la mencionada real cédula parecía querer aplicarse un nuevo recorte al ámbito jurisdiccional de la audiencia tapatía, medida que no sólo afectaba a algunas provincias del norte -Acaponeta y Sentispac- 
sino a otras costeras occidentales e incluso del interior.

Respecto al episodio de 1747 (Pinzón, 2011, pp. 107-109; Yuste, 2000, pp. 21-41), ${ }^{4}$ sabemos que los navíos, el Hervating y el Hersteller, registraban procedencia oriental de Batavia, epicentro de la actividad de la Compañía Oriental Holandesa (Bonialian, 2012, p. 148); pero la alarma generada fue más bien fruto de un temor relativo a incursiones extranjeras y al comercio ilegal con las colonias españolas, que una verdadera y grave amenaza para España en Ultramar. Además el suceso de las naves holandesas no fue un hecho aislado en la historia del litoral pacífico novohispano, y en lo concerniente a las costas noroccidentales hubo varios hechos similares que alertaron de igual forma a las autoridades de Guadalajara para preparar compañías milicianas, y mandar correos y avisos a los alcaldes mayores de la mayoría de las provincias anteriormente mencionadas, con objeto de tomar medidas pertinentes en defensa de los litorales (Pinzón, 2011, pp. 111-112, y 125). ${ }^{5}$

\section{LA TRANSFORMACIÓN DEL PACÍFICO AMERICANO}

Los antecedentes que dieron lugar a la real cédula del año 1750 guardan una estre-

\footnotetext{
${ }^{4}$ Filipinas. 245. AGI, Sevilla. Otro documento del que dan cuenta las autoras es el que tiene por título Sobre el arribo a las costas del Sur de dos navíos holandeses. Guadalajara, 8 de febrero de 1747. Marina. vol. 8, exp. 1. Archivo General de la Nación (AGN), México.

${ }^{5}$ La autora ofrece información sobre el documento titulado Relación de las medidas defensivas tomadas en las costas neogallegas. Guadalajara, febrero de 1746. Filipinas. vol. 3, exp. 5. AGN, México.
}

cha relación con las profundas transformaciones que tuvieron lugar en la regulación de las relaciones comerciales por la Mar del Sur y sobre las rutas transpacíficas desde las últimas décadas del siglo XVII hasta la primera mitad del XVIII. Como telón de fondo debemos mencionar, en primer lugar, el contexto bélico de la guerra de Sucesión iniciada con el cambio de siglo y las incursiones de ingleses, holandeses y franceses a lo largo de las costas pacíficas que afectaban a las comunicaciones intercontinentales, registrándose frecuentes saqueos en puertos como Arica, Patia o El Callao, o bien atacando el galeón de Manila en su travesía regular.

El Pacífico novohispano se encontraba en el punto de mira de la política comercial española por cuanto significaban aquellas costas para la ruta oficial del galeón de Manila y para las conexiones comerciales que con carácter ilegal tuvieron lugar de forma intensa entre Nueva España y Perú entre 1675 y 1740 (Bonialian, 2012, cap. 3). En ambos circuitos transpacíficos la metrópoli quedó al margen de los beneficios obtenidos, pues el comercio que se desarrolló tuvo un marcado carácter intercolonial, y los grandes negocios comerciales fueron capitalizados por filipinos y novohipanos en el primer caso (Yuste, 2007, p. 22), y por estos y peruanos en el segundo eje Perú-Nueva España. Bonialian (2012) analiza la llegada de los navíos peruanos a los puertos occidentales de México y a las costas de Guatemala donde introducían plata, azogue, cacao de Guayaquil o vino peruano, retornando con géneros asiáticos en abundancia y los rezagos de las flotas provenientes tanto del galeón de Manila como de la flota de Veracruz con género de Castilla y Europa. También otros espacios olvidados para la 
metrópoli y para los propios monopolistas mexicanos y limeños se abrirían paso en la circulación de bienes y metales logrando integrar sus mercados con mayor grado de autonomía. Este sería el caso de territorios periféricos del Pacífico como Chile por el sur y el occidente de México por el norte, que con sus puertos y sus hinterland también participaron del comercio intercolonial. Chile en su ruta marítima costanera lo haría a través de Chiloé, Concepción y Valparaíso conectando con los puertos de Arica, El Callao o Guayaquil principalmente; los núcleos de Tepic o Guadalajara lo harían a través de sus costas y enclaves portuarios más significativos como el puerto de La Navidad, Matanchén o años más tarde San Blas. Estos vínculos marítimos a lo largo del litoral pacífico vendrían a completarse con los itinerarios terrestres del continente.

Antes de que acabara el conflicto bélico con Inglaterra, voces y escritos mercantilistas de la época como los de José Campillo y/o de Gerónimo de Uztari pedían un cambio radical en la estructura de la Carrera de Indias, aboliendo el monopolio de Cádiz y el sistema de flotas. También se intentaba impedir el comercio propio de los comerciantes novohispanos por el Pacífico con la consiguiente fuga de metales preciosos al continente asiático, o eliminar la competencia que sufrían los andaluces particularmente en el negocio de la seda (Yuste, 2007, pp. 57-64). Con el fin de la contienda bélica, conocida como la guerra de la Oreja de Jenkins (1739-1748), se sustituía el sistema de flotas y galeones por los navíos de registros como el principal método de las relaciones comerciales entre España y América. Asimismo, a partir de 1748 la ruta del cabo de Hornos iba a ser mucho más uti- lizada, lo que transformaba el escenario marítimo transpacífico al potenciarse un comercio directo entre Chile y Perú; incluso Buenos Aires se incorporaba de forma más efectiva al sistema comercial del imperio, pues una vez abolidos los privilegios de la Compañía del Mar del Sur en 1750 se intensificaron los contactos comerciales en el Río de la Plata. Es decir, entraban en juego nuevos actores del comercio, recuperaban espacio los españoles con sus navíos de registro particulares, y se inauguraba otro sistema de intercambio comercial, factores que alteraron el estado de cosas del comercio ilícito del Pacífico controlado por los poderosos comerciantes mexicanos y limeños a través de sus consulados. La década de los años cuarenta se reconoce como la del inicio del declive del comercio del Pacífico, sobre todo en el comercio ilegal de géneros asiáticos y rezagos de flotas que se realizaban desde los puertos occidentales de Nueva España (Bonialian, 2012, pp. 164-165).

Otras transformaciones vendrían a posteriori en el último tercio del siglo XVIII, cuando se aprobó el reglamento de libre comercio en 1778 , y sobre todo cuando se fundó la Compañía Real de Filipinas en 1785, causando un nuevo golpe de efecto para la tradicional ruta del galeón de Manila con nuevas travesías como la seguida por el Cabo de Buena Esperanza (Alfonso y Martínez, 2013, pp. 307-340). Por otro lado, la Mar del Sur por el litoral mexicano mostraba ya otros circuitos como era El Callao-San Blas, dejando a un lado Acapulco, que ya había perdido la exclusiva del comercio asiático. El género asiático o el americano proveniente del Pacífico sur encontraban además nuevos mercados en Nueva Galicia, Sonora, 
Sinaloa o las Californias a través de las costas noroccidentales.

\section{LAS PROVINCIAS NOMBRADAS PARA EL NUEVO GOBIERNO}

El asunto de los barcos holandeses generó un problema de carácter jurisdiccional entre la capital de México y Guadalajara a través de su Audiencia, dada la duplicación de órdenes expedidas sobre el mismo tema. Esta doble injerencia venía determinada por las jurisdicciones que se encontraban afectadas, unas dentro de los límites de la audiencia de Guadalajara y bajo el gobierno de Nueva Galicia, y otras dependientes en materia de gobierno de la ciudad de México.

Las provincias de Motines, Colima, Sayula, Zapotlán, Autlán, Amula y Etzatlán pertenecían al gobierno de Nueva España, aunque se encontraban, excepto Motines y Colima, subalternadas en temas de justicia a la Audiencia de Guadalajara. Las otras cuatro jurisdicciones restantes, provincias de Purificación, Tepic, Acaponeta y Sentispac, eran manejadas tanto en asuntos de gobierno como de justicia por Nueva Galicia. Posteriormente, bajo la reorganización administrativa y creación de las intendencias de Nueva España en 1786, estas provincias pasaron a depender del gobierno de la intendencia de Guadalajara, exceptuando a Motines -provincia más alejada de la influencia y del gobierno de Nueva Galicia- que quedó como subdelegación de la intendencia de Valladolid, tomando el partido en la década de 1790 el nombre de Motines del Oro o Coaguayana (Gerhard, 1986, p. 199). Las jurisdicciones que formaron parte después de la intendencia tapatía, ocupaban una extensa área que se adentraba hasta el corazón de la región novogalaica, con Etzatlán en el centro, y donde persistió la condición de región marginal respecto al corazón administrativo del virreinato, a pesar de poseer una fuerte personalidad histórica y cultural (Serrera, 1992, p. 46). Izatlán, como se nombra en el expediente analizado, pasó a ser una subdelegación de la intendencia de Guadalajara conocida con el nombre de Ahualulco y Etzatlán (Gálvez, 1996, pp. 70-71), que identificó Van Young (1989) como "área de abasto primario" (p. 26) para la ciudad de Guadalajara, formando parte de su binterland. Otra jurisdicción bien interesante era la de Tepic, pues no sólo era una región clave de las rutas terrestres donde circulaba la plata de El Rosario y el ganado de la zona costera del norte, sino que Tepic era el paso obligado entre las provincias internas de Nueva España y las Californias. El puerto de Matanchén situado en su costa era además el fondeadero principal por el que se adquirían mercancías o maderas.

La región que dependía del gobierno de Nueva España hasta la implantación del sistema de intendencias, aunque estaba situada dentro de los límites de la diócesis de Guadalajara, ${ }^{6}$ había sido muy plei-

\footnotetext{
${ }^{6}$ Nos referimos específicamente a Autlán, Sayula, Amula y Zapotlán. En un mapa sobre los curatos de Nueva Galicia de 1780 quedan perfectamente ubicadas estas provincias bajo el gobierno de Nueva España. Plano que manifiesta la vbicacion, extension, vientos y distancias de todos los curatos que se comprehenden en este Reyno de la Nueva Galicia con el Número de gentes de cada vno: Sugeto y arreglado á los mapas é informes hechos por todos los justicias de su respectiva jurisdiccion: Que junto con el plan de los Oficiales Reales de esta Real Caxa se hará mas comprehensible su producto y número. Se ha formado en virtud de mandato del muy Ilustre Señor Regente y Presidente, Gobernador y Capitan General de este dicho
} 


\section{SECUENCIA}

La intendencia de Guadalajara según la ordenanza de 1786

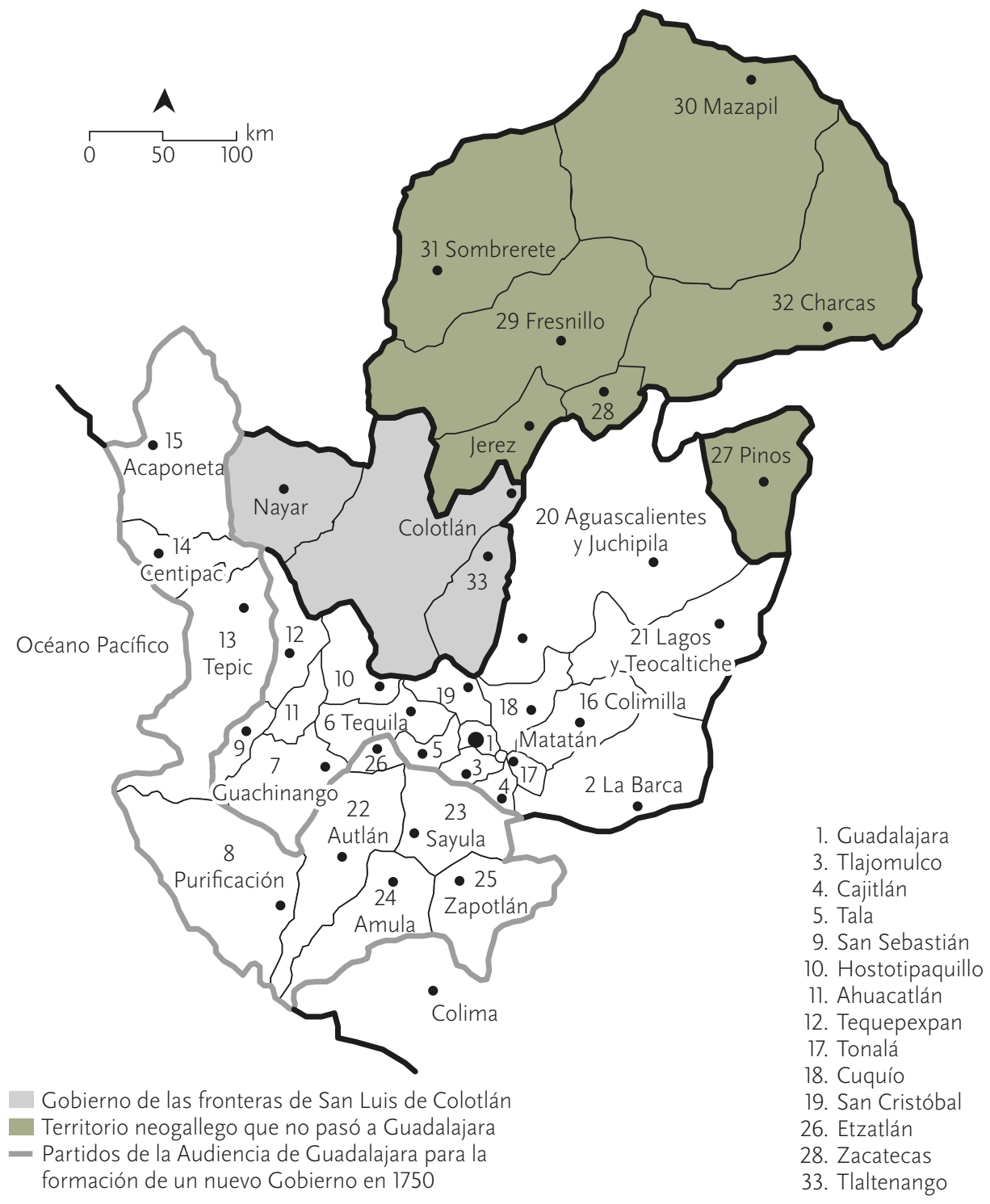

Fuente: elaboración propia a partir de Gutiérrez, J. A. (1991). Los Altos de Jalisco. Panorama bistórico de una región y de su sociedad hasta 1821. México: Consejo Nacional para la Cultura y las Artes. 
teada jurisdiccionalmente desde que Nuño de Guzmán la empezó a reclamar para Nueva Galicia, pero una real cédula de 1533 se la concedió a México. Posteriormente, por otra real orden de 1578, estas provincias quedaron asignadas judicialmente a la audiencia de Nueva Galicia, pero en asuntos de gobierno seguían dependiendo de México hasta el establecimiento de la intendencia de Guadalajara (Gálvez, 1996, pp. 68-69). Respecto a Colima, esta provincia fue también objeto de litigio desde el primer siglo de conquista. Administrativamente pertenecía al gobierno central de Nueva España, pero en materia judicial no quedó del todo clara su situación hasta que por real orden de 1578 se estableció un límite jurisdiccional entre las dos audiencias, otorgando Autlán a Guadalajara, y Colima a México (Gerhard, 1986, p. 81). Hubo que esperar varios años después de la implantación de las intendencias en Nueva España, hasta el año 1795 , para que Colima fuera agregada junto a los reales de minas del Oro y del Favor a la intendencia de Guadalajara, ${ }^{7}$ siendo tal transferencia no sólo en materia de gobierno sino también en asuntos de apelaciones judiciales a la audiencia tapatía (Gálvez, 1996, p. 75).

De las provincias mencionadas para el nuevo gobierno se hallaban internadas, sin costa alguna, Etzatlán, Sayula y Zapo-

Reyno Don Eusebio Sanchez Pareja, por Don Domingo Anastasio Ponze, en consecuencia de Real Orden de 21 de Enero de 1772. Mapas y Planos. México, 360. AGI, Sevilla.

${ }^{7}$ Testimonio del Expediente formado por el Sr. Regente de la Audiencia de Guadalajara sobre haber declarado el Excmo Sr. Presidente que a ella tocan las apelaciones de los partidos de Colima y Reales del Favor y del Oro. Superior Gobierno. Año de 1796. Guadalajara, 364. AGI, Sevilla. (Gálvez, 1996, p. 72). tlán. El resto dibujaba un amplio arco en dirección noroeste por la costa pacífica, encontrándose primero Motines, seguido de Colima, Amula, Autlán, Purificación, Tepic, Sentispac y, por último, en el extremo norte, Acaponeta. ${ }^{8}$ Todas formaban parte del litoral noroccidental mexicano de la Mar del Sur, y en sus costas se encontraban algunos puertos y bahías, o varios esteros y surgideros, de los que trataremos más adelante. En cuanto a Amula y Autlán, situadas en el suroeste de Jalisco, sus jurisdicciones se extendían hacia los valles costeros hasta el mar, ocupando una estrecha franja costera pero de gran valor geoestratégico, al hallarse en el extremo sur de la jurisdicción de Autlán el puerto de La Navidad.

Cabe preguntarse por el interés que las costas de Nueva Galicia habían despertado desde finales del siglo XVII, ya que entonces se idearon nuevos proyectos para redescubrir el Pacífico y explorar las partes más septentrionales de la Mar del Sur. A la presencia rusa en el Pacífico norte y su expansión por Alaska, y a las numerosas expediciones europeas buscando el famoso paso del noroeste, se sumaron las expediciones españolas del Pacífico ilustrado no sólo por intereses comunes sino también como respuesta a esa intervención sobre todo de ingleses y rusos por la costa oeste de América del Norte (Bernabeu, 1992, pp. 190-198). El proyecto de un nuevo gobierno que englobara las costas noroccidentales de Nueva España se

\footnotetext{
${ }^{8}$ Tras el sistema de intendencias, Autlán terminó por conocerse como Autlán de la Grana, nombre al parecer dado por la abundante cochinilla que había en las pencas de nopal de la región. Y Purificación transformó su nombre por Tomatlán (Gálvez, 1996, pp. 70-71).
} 
debe entender tal vez como parte de esos deseos de expansión de la corona española hacia el norte y la península de California. Muriá (1994) señala lo siguiente:

Desde fines del siglo XVII se empezó a ver mayor movimiento en las costas de Nueva Galicia en virtud de que las autoridades españolas empezaron a interesarse en asentar sus reales en tierras norteñas aún no colonizadas y propiciar viajes en tal dirección. La idea era oponerse a ingleses y franceses y, más tarde, a los rusos que querían participar de las riquezas de los litorales americanos en el Pacífico (p. 54).

Así pues hubo varias expediciones por las Californias durante los siglos XVI y XVII, pero la de 1683 , protagonizada por los jesuitas Eusebio Kino, Juan María de Salvatierra y Juan de Ugarte, fue la que logró consolidar un asentamiento español en aquellas tierras. El Nayar era otro espacio por el Pacífico a reducir con los belicosos coras y huicholes, cuyos intentos de sometimiento datan del segundo cuarto del siglo XVII, con varias expediciones en los primeros años de la centuria siguiente, donde tuvieron un papel primordial el franciscano Margil de Jesús en la empresa de 1709 promovida por la Audiencia de Guadalajara, o el capitán de Jerez Juan de la Torre en las negociaciones de pacificación hacia 1721. En tales entendimientos con los indios estuvieron muy presentes concesiones como la adquisición de la sal o el libre acceso a Acaponeta y Mezcaltitán por el Pacífico. No obstante, la lucha contra los nayaritas fue inevitable hasta someterlos y conquistar otra tierra al norte con el nombre de Nuevo Reino de Toledo, nuevo territorio dependiente en lo político del virrey, y en lo judicial de la
Audiencia de Guadalajara (Muriá, 1994, pp. 54-56).

Después, en la segunda mitad de la centuria ilustrada, y como consecuencia del incremento de los avances enemigos, se preparaban nuevas expediciones como la Santa Expedición en 1769 (Bernabeu, 1992, pp. 192 y 199). A partir de estos años, San Blas era el enclave oficial de partida para la guerra de Sonora, el abastecimiento de la Baja California y los presidios del norte, o la expansión hacia la Alta California.

\section{LOS INFORMES DEL CASTELLANO DEL PUERTO} DE ACAPUlCO Y DEL FISCAL DE MÉXICO

Coinciden estos años de mediados de siglo con el mandato del virrey Juan Francisco de Güemes y Horcasitas, recién titulado conde de Revillagigedo. Sin duda se trata de un personaje de gran carisma y relieve político, muy proclive a las reformas que pusieron en marcha los Borbones sobre la anticuada estructura administrativa colonial. El conde de Revillagigedo respondió a la real orden de 1750 con fecha 21 de diciembre de 1752, con dos informes adjuntos, de los cuales hay copias en el documento consultado.? Uno de ellos había sido emitido por el coronel don Juan Eusebio Gallo y Pardiñas, castellano del Fuerte de San Diego de Acapulco, ${ }^{10}$ y el otro provenía del fiscal de la Audiencia de México, el doctor Andreu y Ferraz. ${ }^{11}$

\footnotetext{
${ }^{9}$ México. 1.349, 15 fojas iniciales sin foliación seguidas de las fojas 1r a 40v. AGI. Sevilla.

${ }^{10}$ México. 1.349, fs. 2v-20v. México, 14 de agosto de 1751. AGI, Sevilla.

${ }^{11}$ México. 1.349, fs. 20v-40r. México, 12 de agosto de 1752. AGI, Sevilla.
} 
Interesan ambos informes tanto por la riqueza informativa que contienen sobre las regiones y sus costas, como por las argumentaciones que presentan contrarias a la segregación de un amplio territorio donde debería formarse el nuevo gobierno. En cuanto a lo primero, se puede obtener de cada una de las provincias implicadas en el proyecto una información muy valiosa desde el punto de vista geográfico y humano, detallando su ubicación regional, las distancias en leguas en relación con otras localidades o puntos geográficos, la situación de sus costas, el clima, las producciones más relevantes, e interesantes datos demográficos sobre el número de vecinos o familias, $\mathrm{y}$, a veces, su composición étnica; también para algunas jurisdicciones se ofrece un recuento de tributarios. Respecto a las argumentaciones y razonamientos que no aconsejaban el establecimiento de un nuevo gobierno, ambos dictámenes reflejan la mentalidad que en materia de defensa militar y de organización estratégica territorial sustentaba el castellano del fuerte de San Diego, y que el fiscal de la audiencia de México avaló prácticamente en su totalidad. Como se ha señalado, Gallo y Pardiñas había sido comisionado como persona "idónea y capacitada a efectos militares y de la integridad territorial de Nueva España” (Calderón, 1979, p. 135).

Sobre la figura de Gallo y Pardiñas menciona Bonialian (2012) los estrechos contactos de este apellido y su familia, que durante la primera mitad del siglo XVIII se hizo cargo de la alcaldía de Acapulco, con los almaceneros de México, especialmente por su complicidad en las irregularidades cometidas sobre el tráfico del galeón. Parece que la tolerancia al contrabando y al comercio ilícito era una constante entre autoridades locales y funcionarios portuarios, envueltos en corruptelas de todo tipo a cambio de pingües beneficios. Si esto era así, sin duda los acuerdos de los funcionarios locales con los contrabandistas se debieron intensificar en los considerados "territorios marginales”, ante la impotencia o incluso la permisividad de los virreyes (Fisher, 1992, p. 152).

En relación con el dictamen emitido por Eusebio Gallo sobre el proyecto del nuevo gobierno, declaró al inicio de su informe no poseer un conocimiento exhaustivo de las provincias propuestas para el nuevo gobierno, aunque afirmaba su autoridad en la materia por el contacto asiduo que mantenía con los habitantes de aquellas regiones occidentales a través de los barcos que llegaban al puerto de Acapulco y recalaban antes en aquellas costas y ensenadas del Pacífico desde las Californias. Se mencionaba en este sentido los viajes de ida y vuelta pasando por el cabo de Corrientes, la llegada de la nao de China, y los barcos que desde Acapulco cargaban provisiones rumbo a las misiones jesuitas en las Californias o para el presidio de Loreto.

Nada halagüeño fue el panorama descrito por el coronel en cuanto al clima, las producciones o los habitantes de aquellas jurisdicciones. Tal vez una percepción tan poco afortunada del lugar sólo pueda explicarse por el afán de no llevarse a buen puerto la idea de un nuevo gobierno en aquellas tierras. Así lo expresaba en el informe:

en el Clima todas las mencionadas Provincias participan de una ardentía que si sus avitantes se mantienen es por ser patrio suelo que no ay viviente que no tenga amor al 
citio en que nace y desde Acapulco hasta dar buelta al Cavo de Corrientes están sugetos a unas fiebres y tercianas que desde que empieza el verano hasta terminar el otoño adolesen de estos y otros males y si crece la intemperie muere muchísima Gente... La gente es desinclinada al travajo, pues en hallándose con algún Maís y Leche de algunas Bacas que suelen tener no se fatigan por otros haveres. ${ }^{12}$

Para Gallo sólo las provincias internas de Sayula, Zapotlán, Amula y Etzatlán podían contar con otro tipo de vecinos "menos desidioso que los de la costa".13 Pero lo cierto es que la población indígena de estas regiones costeras fue muy útil en funciones de vigías, en la actividad de la pesca y del comercio local, y su eficacia más notable pudo estar relacionada con los trabajos en los puertos bajo el sistema de repartimiento (Pinzón, 2011, pp. 70-71). Además, en términos generales, los vecinos del litoral neogallego se empleaban en las embarcaciones y navegaciones locales y de cabotaje que tuvieran lugar de manera temporal o coyuntural (Pinzón, 2011, pp. 84-85).

El castellano de Acapulco contrapuso a las argumentaciones expresadas en la real cédula de octubre de 1750 una serie de reflexiones que le permitían concluir que sólo una útil y legítima defensa, con armas adecuadas y pertrechos militares suficientes, podía repelar al enemigo y evitar saqueos en las poblaciones vecinas. Según se expresaba en el informe, las costas referidas tenían varias playas abiertas a la Mar del Sur, sin ningún tipo de vigilancia, ni

\footnotetext{
${ }^{12}$ México. 1.349, fs. 5r-5v. AGI, Sevilla.

${ }^{13}$ México. 1.349, fs. 5v-6r. AGI, Sevilla.
}

cañones o artillería para su defensa, lo que hacía inútil cualquier intento de un nuevo gobierno. Se aconsejaba, por consiguiente, equipar y armar convenientemente al vecindario, y auxiliarlos con alguna ayuda de costa, además de extremar la vigilancia de las costas con dos o tres navíos de guerra que recorrieran el litoral de la Mar del Sur. Parece que la defensa de la costas neogallegas y la formación de milicias locales (Pinzón, 2011, p. 197-204) eran las cuestiones claves a abordar para evitar sucesos como el de 1747. Para dar peso a su propuesta de una mayor y mejor defensa de la costa, se comparaba este hecho con otro acaecido años atrás, en 1742 , cuando al almirante George Anson se le impidió hacer aguada o tomar provisiones por las costas de Zihuatanejo ${ }^{14}$ gracias a la movilización y resistencia de las poblaciones vecinas (Pinzón, 2008b, pp. 63-86).

Uno de los argumentos que en nuestra opinión posee mayor interés fue el que señalaba el nuevo recorte que podría volver a sufrir el gobierno de Nueva Galicia en términos jurisdiccionales, haciendo alusión a la división que ya había tenido lugar a raíz de la real orden del año 1732, por la que se separó de la gobernación novogalaica la región de Culiacán con el real de minas El Rosario. Así expresaba el informe de Gallo sobre este particular:

quedará el de la nueva Galicia con mui corta Jurisdicción, respecto a que por Real Zédula de catorze de marzo del año pasado de mil setezientos treinta y dos se les desmembraron las Provincias de Culiacán y la del Rosario; y a la Nueva Vizcaya las de Sonora,

${ }^{14}$ México. 1.349, f. 8r. AGI, Sevilla. 
Hostimuri y unieron a Sinaloa de las quales consta esta Governación. ${ }^{15}$

La real cédula de 1732 fue remitida al virrey ordenando que las cinco provincias de Sinaloa, Sonora, Ostimuri, El Rosario y Culiacán se unieran bajo un solo gobierno que estuviera "bajo el comando del de Sinaloa” (Catálogo, 2001, p. 51), orden que se hizo efectiva en 1734 al erigirse San Felipe y Santiago de Sinaloa como gobierno separado.

Concluía el castellano de Acapulco indicando similares circunstancias en otras provincias costeras, sin defensa alguna ni tampoco proyecto de gobierno independiente para las mismas. El coronel se refería a las provincias de Igualapa, Xicayan, Huamelula y Tehuantepec, a la parte oriental de Acapulco.

El fiscal Andreu, ${ }^{16}$ el 12 de agosto de 1752, en la ciudad de México, daba a conocer su parecer mediante otro informe, también opuesto al proyecto del nuevo gobierno. El doctor Andreu se basaba en el dictamen anterior, de tal manera que reproduce casi de forma literal las argumentaciones del castellano del fuerte de San Diego. También añadía otros elementos de cierto interés, al incluir información adicional sobre algunas de aquellas provincias, relativas a su ubicación geográfica, clima, recursos humanos o principales actividades económicas y productivas de cada región.

Pese a que el informe del fiscal también era negativo, este se aventuró a hacer

${ }^{15}$ México. 1.349, fs. 16r-16v. AGI, Sevilla.

${ }^{16}$ D. Antonio Andreu y Ferraz, oriundo de Barbastro, Aragón, fue nombrado fiscal del crimen de la Audiencia de México el 30 de marzo de 1738 (Burkholder y Chandler, 1982, pp. 17-18). alguna recomendación en caso de erigirse el nuevo gobierno, considerando como alcaldía más apropiada para la sede del nuevo gobierno la de Autlán, entre varias razones "porque - decía- tiene en su recinto el Puerto de Navidad". ${ }^{17}$

Serrera (1979) señala, al referirse a la descripción que se hizo del distrito de Colima, que en el informe del fiscal se copian párrafos enteros del Theatro Americano de Villaseñor, pero que el texto también ofrece novedades sobre todo en relación con los datos y cifras de los habitantes de la provincia, porque en tal descripción se incluye un nuevo recuento de tributarios que se había realizado hacia la mitad de 1749. Hemos podido comprobar que para el resto de las jurisdicciones descritas ocurre otro tanto, y que por tanto la fuente principal del fiscal fue, además del informe del castellano de Acapulco, las noticias ofrecidas por el Theatro Americano. Incluso se llegan a copiar literalmente algunas partes. Sin embargo, cabe decir que el fiscal reprodujo una mínima parte de las noticias del Theatro, por lo que las descripciones que realiza jurisdicción por jurisdicción, adjuntas a su informe, resultan pobres en términos generales. Y al igual que para Colima, las noticias ofrecen datos de población y, para ciertas provincias, un recuento actualizado de tributarios de hacia mediados de siglo, algo novedoso, no hallado en el Theatro de Villaseñor.

En segundo lugar, nos interesa destacar la relación que hay entre el documento y el Theatro Americano, pues tanto uno como otro fueron producto de la época en que surgieron. Se trata de un periodo

\footnotetext{
${ }^{17}$ México. 1.349, f. 37r. AGI, Sevilla.
} 
donde se dibujaban los prolegómenos de lo que sería la etapa siguiente con la llegada de Carlos III al trono y el plan de profundas reformas económicas y administrativas que se llevarían a cabo en la América española. Estamos, pues, en la antesala de la remodelación de los territorios ultramarinos. Tanto el documento que estamos analizando, con los informes aludidos, así como la confección de obras de gran envergadura como la del propio Villaseñor, son claros ejemplos de lo que estamos diciendo. Sin duda, la impresión del Theatro entre 1746 y 1748 como la primera geografía general de todo el virreinato de México, exceptuando Yucatán, fue la fuente principal de la que echaron mano todos los funcionarios coloniales en los años siguientes. El coronel Gallo y el fiscal Andreu de México debieron de igual forma conocer y leer el texto recién impreso.

De los informes o documentos que contienen relaciones geográficas de la Nueva Galicia a partir del siglo XVIII tenemos información de más de 18 informes, visitas o relaciones geográficas entre 1742 y 1805 (Menéndez, 1980, pp. 16-18), siendo uno de ellos el referido informe del fiscal Andreu del año 1752 sobre los distritos litorales. La mayoría de estos informes o noticias pertenecen a la segunda mitad del siglo XVIII, y sólo tenemos constancia para la primera mitad de las descripciones que hizo Matías Mota Padilla en su Historia del reino de la Nueva Galicia en 1741; y de las Relaciones Geográficas de $1743-1746^{18}$ y del Theatro Ame-

${ }^{18}$ Las Relaciones Geográficas de 1743-1746 fueron preparadas por los alcaldes mayores para dar cumplimiento a una real cédula de Felipe V de 19 de junio de 1741. El virrey, conde de Fuenclara, encargó ricano, ambos en estrecha conexión y como antecedentes directos del informe de 1752. Una fuente que salió a la luz hace pocos años es la de un documento que realiza una descripción detallada de las costas del Pacífico novohipano y de la derrota seguida desde Nueva España a Filipinas, donde se ofrece una valiosa información acompañada de imágenes sobre los puertos, los perfiles de la costa, la ubicación respecto a ríos o poblaciones, etc., pero el texto también data de la segunda mitad del siglo XVIII, con fecha del 5 de enero de 1764 (Pinzón, 2008a, pp. 157-182).

\section{LA FUNCIÓN DE LOS PUERTOS NOROCCIDENTALES}

Es indudable la función que tuvieron los puertos noroccidentales de México en la comunicación costera y de Ultramar. Ahora bien, varios factores nos explican tanto su desarrollo e importancia como el proceso de declive que sufrieron algunos de ellos. No sólo los recursos naturales de las regiones costaneras y su hinterland determinaron tempranamente cierto protagonismo sino también las políticas económicas de los gobiernos colonial o republicano de turno.

Desde la conquista de México se aprecia un interés por aquellas costas para servir de punto de partida de las expediciones que se dirigían a las Californias o a las islas de la especiería en Asia. Muy pronto Acapulco se convirtió en uno de los nudos

a Sahagún de Arévalo y a Villaseñor y Sánchez la elaboración del cuestionario para los datos a recabar en dichas Relaciones, que fueron utilizadas por Villaseñor para la obra del Theatro Americano (Florescano y Gil, 1976, vol. 2, pp. 8-9; Gerhard, 1962, p. 51). 


\section{SECUENCIG}

Principales puntos de la costa del Pacífico novohispano

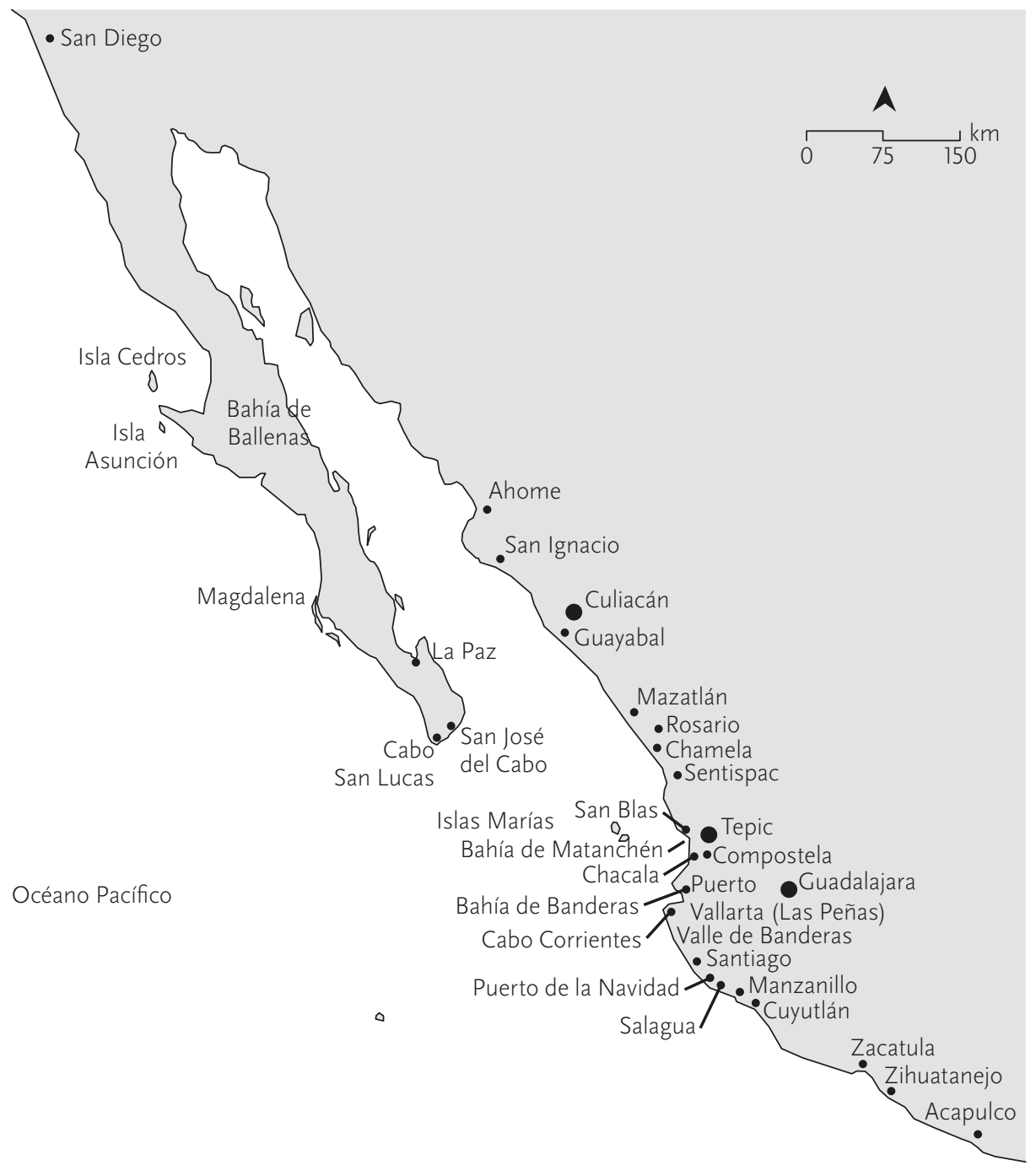

Fuente: elaboración propia a partir de Muriá, J. M. (1991). Breve historia de Jalisco. Guadalajara: Secretaría de Educación Pública/Universidad de Guadalajara. 
principales del comercio pacífico, relegando a un segundo plano buena parte del litoral occidental mexicano, donde la falta de vigilancia y protección de sus costas favorecieron la piratería, el contrabando y el comercio ilícito intercolonial. No obstante, los puertos de Nueva Galicia no sólo fueron objeto de piratas o de intercambios ilegales, sino que también sirvieron de base para las expediciones a las Californias, para la expansión colonizadora del noroeste novohispano, o para la explotación de los bancos de perlas.

Sobre los puertos, enclaves o fondeaderos que se hallan ubicados en las costas noroccidentales de México destacamos a continuación aquellos que, mencionados en el informe del fiscal Andreu, tuvieron un valor singular hacia la mitad del siglo XVIII.

Comenzando la línea de la costa por la jurisdicción de Motines, el partido contaba con algunos surgideros donde podían dar fondo las naves, y con vigía en la costa que además de avistar las embarcaciones que pasaran por el lugar, registraba siempre el "barco que suele cruzar de California y otras cualesquiera que arriban para dicha Costa". ${ }^{19}$ Añade el Theatro que "en su bogeo para Acapulco, se halla un puerto llamado Santelmo, donde dio fondo una Nao este año" (Villaseñor y Sánchez, 1748, p. 99).

A dieciocho leguas de la villa de Colima se encuentra la bahía de las Manzanillas, a donde suelen llegar algunas embarcaciones para suministro de agua, leña y otros “menesteres". ${ }^{20}$ Villaseñor y Sánchez (1748) menciona a los indios del pueblo

\footnotetext{
${ }^{19}$ México. 1.349, f. 26v. AGI, Sevilla.
}

${ }^{20}$ México. 1.349, f. 26v. AGI, Sevilla. de Totolmaloyan por sus servicios de centinelas en la bahía inmediata a Salagua "para dar pronto aviso quando cruza por aquella costa el galeón de China para el puerto de Acapulco" (p. 87). Sobre las costas también se conocía el Puesto de Miraflores, que se encontraba inmediato al cerro de la Centinela, mirando al mar, y en el que estaba fundada una vigía (Villaseñor y Sánchez, 1748, p. 88).

Igualmente tocando a las costas colimenses, en la bahía de Manzanillo, se encuentra el puerto llamado Santiago de Buena Esperanza. Este puerto junto al de La Navidad tuvo cierto protagonismo desde época temprana con las expediciones que se prepararon en aquellas costas por Cortés de San Buenaventura cuando llegó a Colima en 1524 (Reyes, 1994, p. 50). Tres años más tarde se organizaba la primera expedición a las islas del Maluco o de la Especiería, siendo Santiago el primer lugar donde llegaron las naves que días antes habían partido desde Zacatula; a partir de entonces varias naves españolas arribaron en años siguientes, y una segunda expedición en el año 1533 partió del mismo puerto (Reyes, 1994, pp. 5455). Parece que la función del enclave portuario fue parecida a la de La Navidad, al servir para reclutar gente en las expediciones desde el siglo XVI y para bastimento. La ubicación del puerto en la bahía de Manzanillo, que la conforman las dos ensenadas de Santiago y Salagua, separadas entre sí por la península de la Audiencia o de Santiago, vincula su historia a la historia de Manzanillo. No parece que en el puerto de Santiago hubiera un asentamiento español permanente al menos en los siglos XVI y XVII, y en cuanto a su protagonismo durante la colonia se redujo a funciones de puerto de cabotaje, quedando 
en segundo plano en la categoría de puertos menores frente a otros como el de La Navidad mismo (Reyes, 1994, p. 64).

Próximo a Santiago se halla el puerto de Manzanillo, que actualmente es cabecera del municipio llamado de igual manera, situado también en el estado de Colima. Disponemos de pocos datos sobre el periodo colonial, salvo que recibió distintos nombres: Xucutlan, Salagua, y puerto de Colima, afianzándose el nombre de Mazanillo a fines del periodo colonial, que según Ochoa (1994) "se volvió común hacia 1824, cuando dos pilotos británicos elaboraron una carta de la ensenada” (p. 113). Un año después el puerto fue habilitado para el comercio con el extranjero, pero la competencia comercial de San Blas y Mazatlán lo eclipsaron de manera continuada.

Aunque en la descripción que hace el fiscal de México del partido de Autlán no se menciona el puerto de La Navidad, dicha jurisdicción incluía tal fondeadero, que tuvo funciones complementarias a las del puerto de Acapulco en las rutas transpacíficas. La Navidad se convirtió en un astillero español en la época de la conquista, sirviendo como punto de partida de las primeras exploraciones españolas hacia la Mar del Sur, rumbo al Pacífico norte y a las Filipinas. Olveda (1994) señala la función que tuvo este puerto en las expediciones que se hicieron a las Californias desde Nueva España en el desarrollo del comercio de cabotaje y en la aparición de las primeras empresas interesadas en los bancos de perlas. Aunque su importancia mayor se debe a la expedición que se proyectó por Miguel López de Legazpi y fray Andrés de Urdaneta para conquistar las Filipinas, culminando con el éxito de la ruta descubierta a aquellas islas con el tornaviaje de Urdaneta (Gil, 2013, pp. 25-64). Fue entonces cuando se desarrolló un comercio transoceánico por el Pacífico hispano de gran calado, aunque este inmediatamente fue capitalizado por los grandes comerciantes de la ciudad de México. No obstante, el puerto de La Navidad no fue considerado por Urdaneta como el lugar más adecuado para recibir al galeón de Manila, siendo inmediatamente desplazado por el de Acapulco (Mota y Escobar, 1993, p. 33), pero dado que el galeón de Filipinas en su navegación desde California a su destino final navegaba "a vista de tierra" para reparaciones o para proveerse de agua y de otros recursos, la escala en La Navidad, así como en otros puertos de Nueva Galicia, se hizo de forma reiterada, anunciando desde estas costas a la Audiencia de Guadalajara y a la capital virreinal el próximo arribo de la nao a Acapulco. Tales escalas de la nao de China sirvieron sin duda para introducir de forma clandestina mercancías asiáticas por el litoral noroccidental (Olveda, 1994, p. 25). Igualmente los navíos provenientes de Guayaquil, El Callao o incluso de Valparaíso, rumbo a Acapulco, aprovecharon los diversos fondeaderos -a Navidad, Matanchén o San José del Cabo- para introducir ilegalmente en sus barcos los géneros asiáticos y desarrollar un comercio ilícito de signo interamericano.

La cuestión del intercambio comercial de género asiático con productos de la tierra en el litoral novogalaico era bien conocida desde los inicios de la ruta del tornaviaje de Urdaneta, y así lo refiere en varias ocasiones Mota y Escobar (1993) en su descripción que hizo de Nueva Galicia hacia 1605 o 1606, señalando de los vecinos de Villa Purificación que 
"algunos tratan en mercadería de China y ropa de la tierra” (p. 32); y que en el puerto de Chacala "vienen a surgir los barcos de contratación de particulares que van a Acapulco a emplear en ropa de China y vinos del Pirú, y otros tienen grangerías en la sal que traen a vender de la provincia de Culiacan" (p. 34).

Indicaba el fiscal Andreu en su informe que al Puerto de Santiago le seguía por la línea de la costa el Valle y Puerto de "Valderas" y después el puerto de Matanchén, perteneciente a la jurisdicción de Tepic. ${ }^{21}$ El Theatro ofrece una información complementaria sobre este tramo de costa mencionando el pequeño pueblo de Tomatlán y sus vecinos que hacían de "vigías para descubrir los tránsitos de los Navíos, y son los que primero avistan el galeón de Philipinas" (Villaseñor y Sánchez, 1748, p. 245).

La bahía de Banderas, al norte limita por la Punta de Mita y por el sur con el cabo de Corrientes; y la jurisdicción más próxima es la de Purificación. Munguía (1994) señala que "en su entrada, se encuentran unos islotes llamados las Marietas, y en su ápice, cruzado por el río Cuale, se localiza Puerto Vallarta, antes conocido con el nombre de Las Peñas o Peñitas" (p. 135). La bahía contaba con varios fondeaderos y era visitada por los balleneros y comerciantes que burlando la aduana de San Blas introducían sus mercancías al Valle de Banderas, Mascota y San Sebastián. Además, la cercanía de algunos centros mineros le confirió a esta rada una importancia singular, al poderla utilizar para exportar su producción e introducir los productos necesarios para

${ }^{21}$ México. 1.349, f. 31r. AGI, Sevilla. los centros mineros, entre ellos la sal para el beneficio de la plata, producto trasladado en lancha desde San Blas o las islas Marías a alguno de los fondeaderos de la bahía (Munguía, 1994, pp. 136-137). La bahía de Banderas fue referente seguro para el galeón de Manila; se sabe que en 1620 este no pudo llegar a Acapulco arribando a la bahía, después de haber perdido a casi cien personas de la tripulación por el escorbuto y otras enfermedades en la larga travesía (Bernabeu, 1992, p. 70).

La ubicación de la jurisdicción de Tepic en relación con sus costas nos la precisa Gerhard (1996) en su Frontera norte. Dicha jurisdicción tiene en sus costas el llamado puerto de Matanchén, que actualmente se conoce como una bahía y pequeña localidad situada en el estado mexicano de Nayarit. Parece que esta bahía junto al puerto de San Blas y la playa Las Islitas fue refugio de piratas y bucaneros. También Matanchén destacó como centro perlero y como depósito de bastimento de las misiones jesuitas de California (Gerhard, 1996, p. 181). Al igual que los otros puertos mencionados sirvió de apoyo y base a las expediciones marítimas del Pacífico, sobre todo cuando Compostela, como antigua capital de Nueva Galicia, estuvo situada en el valle de Tepic entre 1531 y 1540 . No obstante, la importancia del puerto de Matanchén fluctuó a lo largo del periodo colonial según el protagonismo que podían alcanzar otros puertos próximos, siendo su rival principal Chacala (Luna, 1994, pp. 79-81). El puerto de Matanchén contaba con bosques y maderas suficientes para ser el astillero principal, y con una comarca rica para provisiones y pertrechos, pero el mayor inconveniente era la gran cantidad de mosquitos de la zona. Sin embargo, 
Chacala ofrecía menos posibilidades para la construcción de barcos, razón que explica la transición de este puerto a $\mathrm{Ma}$ tanchén definitivamente, fondeadero por el que se adquirían mercancías para su distribución en Nueva Galicia y se obtenía la madera necesaria. Pero lo que mejor explica la notable función de Matanchén hasta más allá de la mitad del siglo XVIII fue el desarrollo económico y administrativo de la provincia de Tepic, como eje articulador de intercambios entre las áreas mineras principales de la región (Luna, 1994, p. 81). El declive de Matanchén vino determinado por el momento en el que se decidió crear un nuevo puerto en aquellas costas del Mar del Sur, cerca del río San Blas, el conocido puerto de San Blas.

Una mención aparte requieren las islas Marías, muy próximas a aquellas costas. Se sabe que a raíz de la inquietud que generó la presencia del capitán Anson por las costas novohispanas, se adoptaron diligencias de todo tipo desde Acapulco hasta los distritos de la Nueva Galicia para impedir el desembarco del inglés, entre ellas las que ordenó el gobernador de Nueva Galicia de recabar ciertas noticias sobre la utilidad de las islas Marías dada su proximidad a los litorales de su jurisdicción. Tal información recogía aspectos positivos como la fertilidad de las tierras para la siembra y la cría de ganado mayor, y la existencia en las costas de tortugas de carey y perlas. Se consideraba a las tres islas apropiadas para la instalación de un presidio, con objeto de apoyar los asentamientos de San José del Cabo (Bernabeu, 2013, pp. 271-305). Desde Matanchén se podrían enviar los bastimentos necesarios, así como prisioneros y vagabundos de Guadalajara (Pinzón, 2013, p. 258), convirtiéndose las Marías en asentamiento para apoyo a las misiones jesuitas y a los presidios de California, y como defensa ante la presencia de los bajeles extranjeros que intentasen capturar el galeón de Manila. Como indica Pinzón (2013), el proyecto de ocupación de las Marías no se llevó a cabo en ese momento, pero fue retomado posteriormente.

Hacia el norte continúa la línea de costa por Sentispac y Acaponeta. Aunque ambos partidos no contaban con puerto sí tenían varios esteros y surgideros. También se tiene noticia de una barrera de playas con salinas y manglares, y una red de lagos y pantanos, producto de las inundaciones estacionales, en Acaponeta (Gerhard, 1996, p. 76).

Por último cabe destacar que los puertos y bahías señalados quedarían pocos años después eclipsados, a la sombra de lo que significó la fundación del puerto de San Blas en el año 1768, impulsado por el visitador José de Gálvez. López (1994) señala varias razones para establecer en el océano Pacífico un nuevo puerto y astillero, entre ellas el facilitar las expediciones hacia Sonora, Sinaloa y Nueva Vizcaya y el envío de ejércitos para la pacificación de las Provincias Internas; en segundo lugar, proteger a la Alta California de las incursiones inglesas y rusas, interesadas en las tierras no colonizadas de América del Norte; un tercer motivo era favorecer los intereses de los comerciantes de Guadalajara para establecer un comercio regular por el Pacífico y controlar los galeones de las Filipinas. Tanto el virrey como el visitador estuvieron de acuerdo con el proyecto de pacificación de las Provincias Internas y con el de establecer una nueva base sólida para nuevas exploraciones por el Pacífico. También se justificaban estos proyectos 
ante el vacío de poder dejado por los jesuitas en amplias zonas donde antes habían ejercido notable influencia y dominio. José de Gálvez y el Consejo de Indias se inclinaron por San Blas frente a Matanchén para el nuevo puerto junto a las dependencias imprescindibles para la defensa de la base naval (Muriá, 1988, p.132). Así, el nuevo puerto fue organizado como departamento marítimo con un comandante naval y un comisario civil (Gálvez, 1996, p. 70), quedando pues San Blas junto a Guaristemba como enclaves militares hasta la independencia. La ubicación de San Blas a mitad de camino entre Cabo de San Lucas y Chamela, donde, señala Muriá (1988), había también fortificaciones para proteger la ruta del "tornaviaje" de Manila a Acapulco, permitía un mayor control y protección del comercio legal frente al contrabando de mercancías extranjeras y a la fuga de plata; y también ofrecía refugio a los galeones de Filipinas respecto a tempestades, o ataques piráticos. Pero además el nuevo puerto ofrecía a la región de Guadalajara otras alternativas diferentes al sistema mercantilista de control de su mercado interno y externo, que sólo había dejado grandes márgenes de beneficios a los monopolistas de la ciudad de México. La economía de centros como Guadalajara y Tepic se consolidaba con este nuevo enclave portuario al permitir el desarrollo del comercio neogallego en esta segunda mitad de la centuria ilustrada (Muriá, 1988, p. 131).

En cuanto a la defensa del litoral, conviene aclarar que si bien estas costas no contaban con destacamentos permanentes, y que el contrabando y la piratería eran una constante, tampoco llegaron a ser descuidadas del todo. Fue la Audiencia de Guadalajara, y no otra instancia o autori- dad ajena a esta región, la encargada de tomar medidas para la vigilancia y defensa de su costa, nombrando alcaldes mayores a cargo de compañías militares temporales que debían ubicarse en algún lugar de la costa (Olveda, 1994, p. 27). Este aspecto corrobora nuestra hipótesis de que aquella parte del litoral mexicano había sido controlada desde siempre por la Audiencia tapatía y sin duda con el paso de los años el control fue de forma creciente. Difícilmente podía prosperar una gobernación independiente del gobierno y audiencia neogallegos.

Queda claro, pues, que los puntos costeros mencionados ocuparon una posición inferior frente a Acapulco y su función fue escasa o pobre en el marco del comercio oficial pero, sin embargo, tuvieron un papel primordial como nudos de tránsito en el comercio informal e intercolonial americano (Bonialian, 2012, p. 154). Es decir, si Cavite, Acapulco y El Callao eran los nudos principales de los flujos mercantiles pacíficos oficiales, otros puertos como los aquí señalados y más al sur, los de Paita, Arica, Trujillo, Piura o Guayaquil, con otros menores de su entorno, también formaron parte indiscutible del tráfico por la Mar del Sur, pero lo hacían en alto grado al margen de los intereses de España o de los consulados de México y Lima.

Por último, se ha de indicar que todavía hacen falta estudios complementarios que nos muestren el desarrollo del comercio de cabotaje que tenía lugar en estas costas occidentales, donde probablemente se producía un intercambio con las poblaciones locales a través de sus playas en pequeñas lanchas. Tampoco hay que descartar que buena parte del género ilícito que llegara a esas costas se internara tierra adentro. 


\section{REFLEXIONES FINALES}

Como se puede apreciar se han presentado las razones que promovieron los informes analizados con sus pruebas, comunicaciones o circunstancias. Aquellos dictámenes emitidos por el castellano de Acapulco y por el fiscal de México responden a los procedimientos habituales de la época para dar cumplimiento a una real orden emitida desde España. Pero tal vez lo que más nos interese de este trabajo es poder calibrar el peso que tuvieron tales informes y sus emisores en los medios oficiales de Nueva España. Se trataba de opiniones contrarias al proyecto de un nuevo gobierno, bien fundamentadas y alejadas de discursos agoreros. Con toda probabilidad lo silenciado en los informes es mucho más de lo que se dice o insinúa en los mismos.

Nos permitimos interpretar entre las causas que dieron al traste con el proyecto del nuevo gobierno, la existencia de un fuerte regionalismo en las provincias comprometidas para el nuevo gobierno, al hallarse casi todas secularmente vinculadas al gobierno de Guadalajara y a su audiencia. Aquí los intereses en juego eran muchos. La preocupación por un férreo control sobre la cuenca noroccidental con sus puertos y ensenadas, no se reducía solamente al paso del galeón de Manila, sino que estas costas habían sido desde el siglo primero de la conquista, y seguían siéndolo en el siglo ilustrado, puntos geoestratégicos de salida y llegada para expediciones, expansiones y acciones de dominio en los territorios más alejados de la capital virreinal.

Desde el punto de vista comercial, la tolerancia al contrabando y tráfico ilícito, en connivencia con las autoridades locales y los propios comerciantes capitalinos, había sido una constante hasta mediados de siglo. Sin embargo, ante el declive que experimentó el comercio pacífico en el circuito oficial Filipinas-Acapulco-ciudad de México, se adoptaron otras reglas de intercambio comercial en las que los comerciantes regionales del Occidente hacían sus tratos directos con los navíos de registros que alcanzaban aquellas costas. Tampoco el contrabando marítimo desapareció ni el comercio directo con el Pacífico sur, pero serían los nuevos agentes comerciales vinculados a Guadalajara, o a Tepic, los que participaran mayormente de aquellos intercambios al margen de los dictados del Consulado de México. Se puede afirmar que el litoral jalisciense había logrado reconocerse como un ámbito de comercialización semiautónomo a mediados de la centuria ilustrada.

Además las regiones costeras conectaban fácilmente con otras ricamente productivas, $\mathrm{y}$ a través de rutas y caminos con los reales de minas más importantes de Nueva España. Los intereses económicos y comerciales de la región occidental eran variados y de notable peso, ante las oportunidades que se presentaban para abrir nuevos mercados. Por lo tanto, la pugna por el control de la parte occidental con sus costas, puertos, bahías y fondeaderos se extendió a lo largo del siglo XVIII e incluso se reavivó cuando se impuso una nueva reorganización territorial administrativa bajo el sistema de intendencias. Los primeros años de vida de la intendencia de Guadalajara asistieron a un proceso de afirmación y consolidación de la identidad regional del occidente de México que perdura prácticamente hasta nuestros días.

La otra resistencia a tal despegue regional se dibujaba desde el centro neurálgico de Acapulco, tratando de eclipsar, aunque 
ya con poco éxito ante su propio declive, este cinturón intermedio de la costa hacia el oeste. Pero la creación del puerto de San Blas en 1768 vino a confirmar la tendencia del momento sobre una región en crecimiento y menos dependiente.

Previamente a la creación de San Blas surgen proyectos como el aquí analizado, son proyectos políticos y militares enunciados ante los primeros síntomas de quiebra y fisuras del imperio, y para dar respuesta a las dificultades por mantener las posesiones españolas en tierras lejanas del norte, o a su suerte en costas abiertas y sin defensa; el proyecto del nuevo gobierno no era más que eso, un intento tal vez ya desesperado por poner coto y control a una región que se escapaba del dominio colonial y hasta del propio control virreinal, y sin embargo era de un interés geoestratégico excepcional. Que la política imperial de la corona española moviera fichas en direcciones tan diferentes y a veces hasta opuestas, no era más que el reflejo de su propia debilidad y de la ausencia institucional en áreas periféricas durante demasiado tiempo.

Tal vez las acciones de saqueo de los navíos extranjeros eran la principal excusa para hacer aquella propuesta de gobierno, aunque en el fondo lo que imperaba era la sujeción de una región con unos intereses cada vez más alejados del centro de México y también de la propia metrópoli, y cuyo desarrollo regional estaba a punto de despegar inaugurándose para la segunda mitad del siglo XVIII un ciclo semicircular de crecimiento para Guadalajara y su región (Ibarra, 2000, p. 101), donde las demandas internas -sobre todo la urbana- y las extrarregionales fueron los grandes motores de desarrollo para las provincias occidentales.

\section{LISTA DE REFERENCIAS}

-Alfonso Mola, M. y Martínez Shaw, C. (2013). La ruta del Cabo y el comercio español con Filipinas. En S. Bernabeu Albert y C. Martínez Shaw (eds.), Un océano de seda y plata: el universo económico del Galeón de Manila (pp. 307-340). Sevilla: Consejo Superior de Investigaciones Científicas.

-Bernabeu Albert, S. (1992), El Pacífico Ilustrado: del lago español a las grandes expediciones. Madrid: MAPFRE.

-Bernabeu Albert, S. (2013). Entre la desconfianza y la indecisión: las relaciones entre el Galeón y las Californias. En S. Bernabeu Albert y C. Martínez Shaw (eds.), Un océano de seda y plata: el universo económico del Galeón de Manila (pp. 271-305). Sevilla: Consejo Superior de Investigaciones Científicas.

-Bonialian, M. A. (2012). El Pacífico bispanoamericano. Política y comercio asiático en el Imperio español (1680-1784). La centralidad de lo marginal. México: El Colegio de México.

-Burkholder, M. A. y Chandler, D. S. (1982). Biographical dictionary of Audiencia Ministers in the Americas, 1687-1821. Westport: Greenwood Press.

-Calderón Quijano, J. A. (dir.) (1979). Documentos para la bistoria del estado de Colima, siglos XVI-XIX. México: Novaro.

-Catálogo de documentos para la bistoria de las misiones (2001). Culiacán, Sinaloa, México: Universidad Iberoamericana/El Colegio de Sinaloa.

-Fisher, J. R. (1992). Relaciones económicas entre España y América hasta la Independencia. Madrid: MAPFRE.

-Florescano, E. y Gil, I. (comps.) (1976). Descripciones económicas regionales de Nueva España. Provincias del Norte, 1790-1814 (vol. 2). México: Instituto Nacional de Antropología e Historia.

-Gálvez Ruiz, M. A. (1996). La conciencia regional en Guadalajara y el gobierno de los intenden- 
tes (1786-1800). Guadalajara, México: Unidad Editorial del Gobierno del Estado de Jalisco.

-Gerhard, P. (1962). México en 1742. México: José Porrúa e Hijos.

-Gerhard, P. (1986). Geografía histórica de la Nueva España 1519-1821. México: UNAM.

-Gerhard, P. (1996). La frontera norte de la Nueva España. México: UNAM.

-Gil, J. (2013). El primer tornaviaje. En S. Bernabéu Albert (coord.), La Nao de China, 1565-1815. Navegación, comercio e intercambios culturales (pp. 25-64). Sevilla: Universidad de Sevilla.

-Ibarra, A. (2000). La organización regional del mercado interno novohispano. La economía colonial de Guadalajara, 1770-1804. México: Benemérita Universidad Autónoma de Puebla/UNAM.

-López González, P. (1994). San Blas. Surgimiento y decadencia. En J. Olveda y J. C. Reyes Garza (coords.), Los puertos noroccidentales de México (pp. 89-108). Guadalajara, Jalisco: El Colegio de Jalisco/Universidad de Colima/INAH.

-Luna Jiménez, P. (1994). Chacala y Matanchén. Dos puertos en el avance hispano a las Californias. En J. Olveda y J. C. Reyes Garza (coords.), Los puertos noroccidentales de México (pp. 75-87). Guadalajara, Jalisco: El Colegio de Jalisco/Universidad de Colima/INAH.

-Menéndez Valdés, J. (1980). Descripción y censo general de la Intendencia de Guadalajara 1789-1793 [estudio preliminar y versión del texto de Ramón $M^{a}$ Serrera]. Guadalajara, México: Unidad Editorial.

-Mota, de la y Escobar, A. (1993). Descripción geográfica de los reinos de Nueva Galicia, Nueva Vizcaya y Nuevo León (ed. facsimilar). Jalisco: Universidad de Guadalajara.

-Munguía Fregoso, C. (1994). Puerto Vallarta. De los balleneros a los cruceros. En J. Olveda y J. C. Reyes Garza (coords.), Los puertos noroccidentales de México (pp. 135-151). Guadalajara, Jalisco: El Colegio de Jalisco/Universidad de Colima/INAH.
-Muriá, J. M. (1988). Breve historia de Jalisco. Guadalajara, Jalisco: Secretaría de Educación Pública/Universidad de Guadalajara.

-Muriá, J. M. (1994). Breve bistoria de Jalisco. México: El Colegio de México/FCE.

-Ochoa Rodríguez, H. P. (1994). Manzanillo. El intricado despertar de un puerto. En J. Olveda y J. C. Reyes Garza (coords.), Los puertos noroccidentales de México (pp. 113-128). Guadalajara, Jalisco: El Colegio de Jalisco/Universidad de Colima/INAH.

-Olveda, J. (1994). La Navidad. El comercio y la penetración filipina. En J. Olveda y J. C. Reyes Garza (coords.), Los puertos noroccidentales de México (pp. 15-34). Guadalajara, Jalisco: El Colegio de Jalisco/Universidad de Colima/INAH.

-Olveda, J. (1996). Conquista y colonización de la costa neogallega (tesis doctoral). Facultad de Filosofía y Letras-UnAm, México.

-Olveda, J. y Reyes Garza, J. C. (coords.) (1994). Los puertos noroccidentales de México. Guadalajara, Jalisco: El Colegio de Jalisco/Universidad de Colima/INAH.

-Pinzón Ríos, G. (2008a). Una descripción de las costas del Pacífico novohispano del siglo XVIII. Estudios de Historia Novohispana, 39, 157-182.

-Pinzón Ríos, G. (2008b). Defensa del Pacífico novohispano ante la presencia de George Anson. Estudios de Historia Novobispana, 38, 63-86.

-Pinzón Ríos, G. (2011). Acciones y reacciones en los puertos del Mar del Sur. Desarrollo portuario del Pacífico novobispano a partir de sus políticas defensivas, 1713-1789. México: UNAM/Instituto Mora.

-Pinzón Ríos, G. (2013). Las islas Marías: enclave estratégico de la ruta del Galeón de Manila. En S. Bernabeu Albert y C. Martínez Shaw (eds.), Un océano de seda y plata: el universo económico del Galeón de Manila (pp. 247-269). Sevilla: Consejo Superior de Investigaciones Científicas.

-Reyes Garza, J. C. (1994). Santiago de Buena Esperanza de la Bahía de Manzanillo. Notas 
y precisiones sobre su historia. En J. Olveda y J. C. Reyes Garza (coords.), Los puertos noroccidentales de México (pp. 39-65). Guadalajara, Jalisco: El Colegio de Jalisco/Universidad de Colima/INAH.

-Serrera, R. M. (1979). Descripción del Distrito de Colima, 1752. En J. A. Calderón Quijano (dir.), Documentos para la bistoria del Estado de Colima, siglos XVI-XIX (pp. 169-170). México: Novaro.

-Serrera, R. M. (1992). Tráfico terrestre y red vial en las Indias españolas. Madrid, Sevilla: Ministerio del Interior. Dirección General de Tráfico/Lunwerg Editores.

-Van Young, E. (1989). La ciudad y el campo en el México del siglo XVIII. La economía rural de la región de Guadalajara, 1675-1820. México: FCE.

-Velázquez, M. C. (1977). La Comandancia General de las Provincias Internas. Historia Mexicana, 27, 163-176.

-Villaseñor y Sánchez, J. A. de (1748). Theatro americano. Descripción general de los reynos y provincias de la Nueva España y sus jurisdicciones (segunda parte). México: Imprenta de la viuda de D. Joseph Bernardo de Hogal.

-Yuste, C. (2007). Emporios transpacíficos. Comerciantes mexicanos en Manila, 1710-1815. México: UNAM.

-Yuste, C. (2000). El eje comercial transpacífico en el siglo XVIII: la disolución imperial de una alternativa colonial. En C. Yuste y M. Souto (coords.), El comercio exterior de México 1713-1850; entre la quiebra del sistema imperial y el surgimiento de una nación (pp. 21-41). México: Instituto Mora/IIH-UNAM/Universidad Veracruzana.

\section{OTRAS FUENTES}

Archivos

AGI Archivo General de Indias. 